\title{
ANÁLISIS GEOARQUEOLÓGICO Y ESPACIAL DE UN YACIMIENTO MUSTERIENSE AL AIRE LIBRE: LA RAÑA DE CAÑAMERO (CÁCERES, ESPAÑA)
}

\author{
GEOARCHEOLOGICAL AND SPATIAL ANALYSIS OF A MOUSTERIAN SITE: LA RAÑA DE \\ CAÑAMERO (CÁCERES, ESPAÑA)
}

\author{
JESÚS FERNÁNDEZ FERNÁNDEZ \\ DAVID ÁLVAREZ ALONSO \\ Departamento de Prehistoria y Arqueología \\ C.A. UNED-Asturias
}

\section{INTRODUCCIÓN}

Durante el mes de julio de 2011 se desarrollaron varios trabajos arqueológicos en el término municipal de $\mathrm{Ca}$ ñamero, Cáceres (Fig. 1) (Álvarez Alonso y Fernández Fernández, 2012). El objetivo de estas intervenciones era valorar una serie de hallazgos superficiales de industrias líticas procedentes de una de las rañas pliocenas que bordean la Sierra de las Villuercas. En consecuencia, se realizó una prospección superficial sistemática y la excavación de dos sondeos arqueológicos, tras lo cual se recuperó un conjunto lítico perteneciente al Paleolítico medio.

En este trabajo intentamos complementar distintos tipos de análisis al objeto de entender, en primer lugar, los procesos geomorfológicos y de alteración postdeposicional (p. e. incidencia del laboreo agrícola, usos del suelo, etc.) a los que ha estado sometido el registro arqueológico que hoy estudiamos, pues cualquier interpretación posterior depende de esta correcta contextualización. Por otro lado, no queremos olvidar que tras cualquier vestigio de cultura material ha habido siempre una acción social que espera ser interpretada. Los cazadores-recolectores paleolíticos, por su movilidad y escaso impacto en el territorio, sólo nos han dejado algunos útiles de piedra en la mayoría de casos y, fundamentalmente, en ambientes al aire libre que hoy son nuestro único punto de apoyo para desentrañar su leitmotiv social. Este registro, generalmente en posición derivada y superficial, no ha sido precisamente el más atractivo para los estudiosos del paleolítico. En nuestro trabajo queremos mostrar que, mediante la integración de distintos métodos y recursos técnicos, podemos avanzar hacia la creación de un marco interpretativo que ponga en valor sus posibilidades.

Para cumplir con estas expectativas trabajaremos a escalas diferentes. Por un lado, analizaremos los

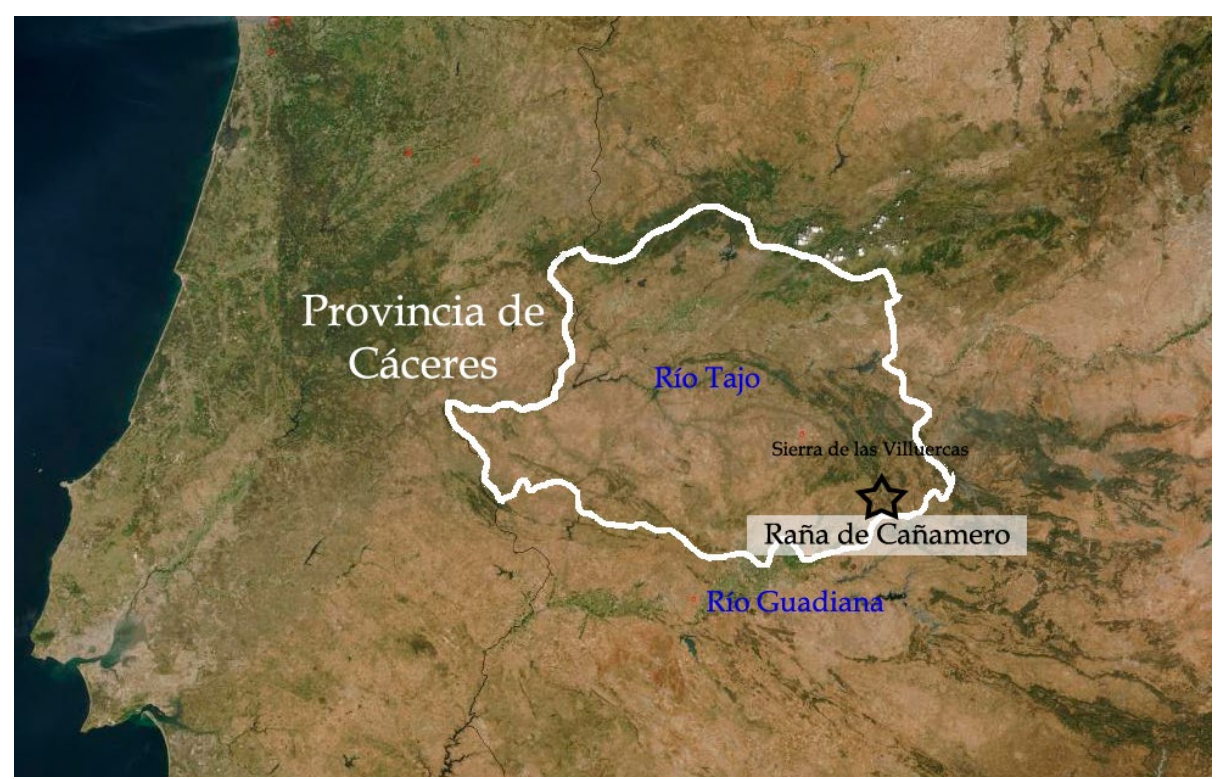

Figura 1: Localización de la raña de Cañamero. 


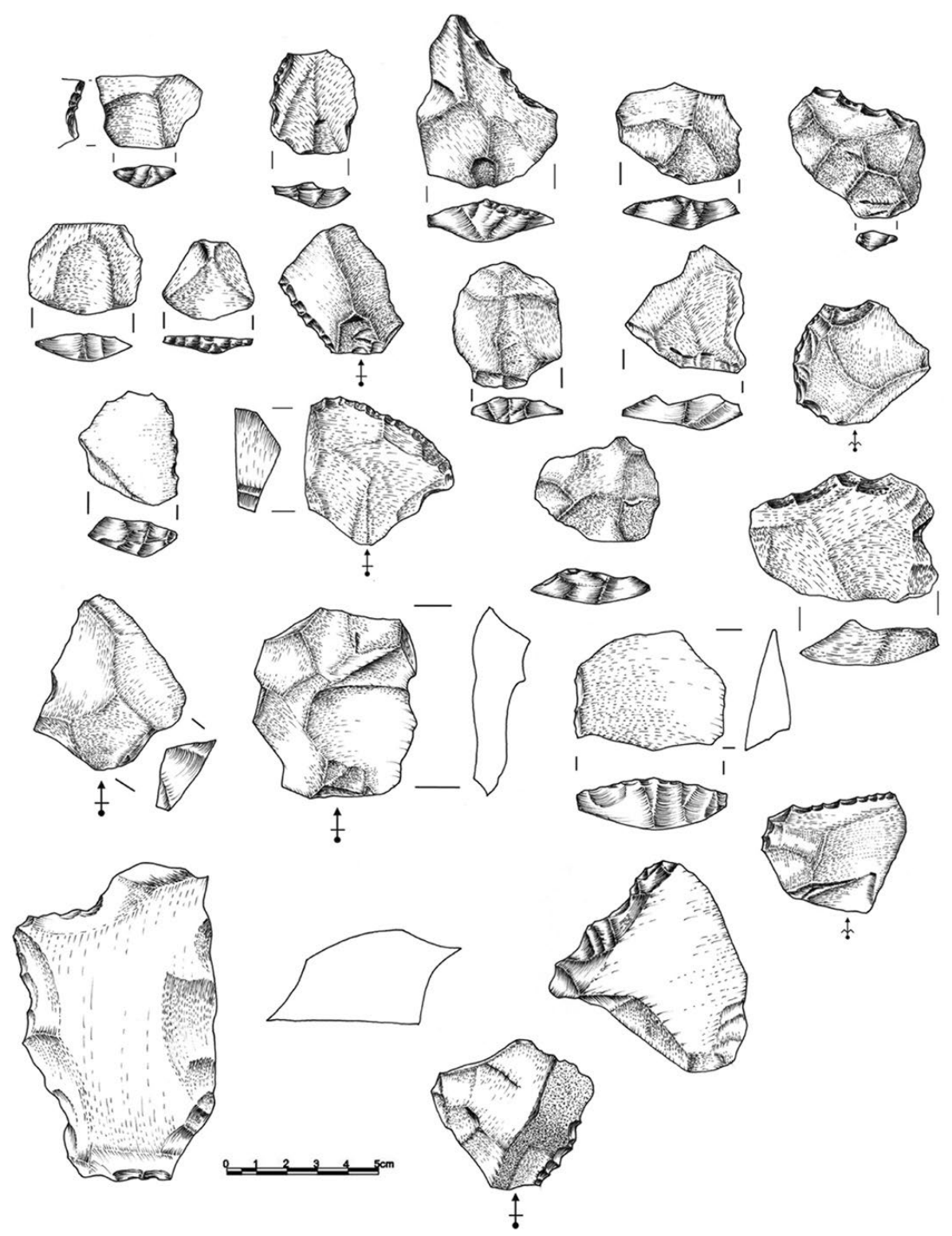

Figura 2: Industria lítica de la raña de Cañamero.

patrones espaciales intra-site del yacimiento, que nos revelarán información sobre posibles usos diferenciales del espacio o sobre los procesos postdeposicionales que lo afectaron. Por otro, intentaremos enmarcar esta información en un contexto geográfico más amplio, al objeto de entender los sistemas de ocupación del territorio en la longue durée del Paleolítico. Relacionamos, de esta forma, los aspectos meramente tecnológicos con aquellos que tienen que ver con procesos medioambientales de interés, o con el uso del territorio.

El conjunto lítico de la raña de Cañamero lo forman un total de 467 piezas líticas (Fig. 2), cuyo estudio tecnotipológico (Álvarez Alonso y Fernández Fernández, 2012), ha servido para encuadrar el tecnocomplejo lítico de Cañamero en un Paleolítico medio genérico. Al estudiar este conjunto desde un punto de vista tafonómico se pudo separar el material en dos grandes conjuntos, según el grado de alteración, presentando ambos grupos características tecnitipológicas casi idénticas, lo cual nos está indicando que no hay separación tecnotipológica con valor diacrónico, a partir de un análisis de pátinas. Por lo que a resultas de este estudio, pudimos interpretar que las alteraciones de la industria lítica eran postdeposicionales y se debían a un alteraciones tafonómicas diferenciales, dentro del mismo conjunto. Por esta razón se planteó un estudio espacial y geoarqueológico, para poder interpretar mejor el proceso de alteración del conjunto y su integridad desde un punto de vista tecnotipológico y cronológico.

En definitiva, el objetivo global de nuestro trabajo es contribuir a la mejor compresión de la génesis y evolución de las ocupaciones al aire libre del Paleolítico medio en la región. 


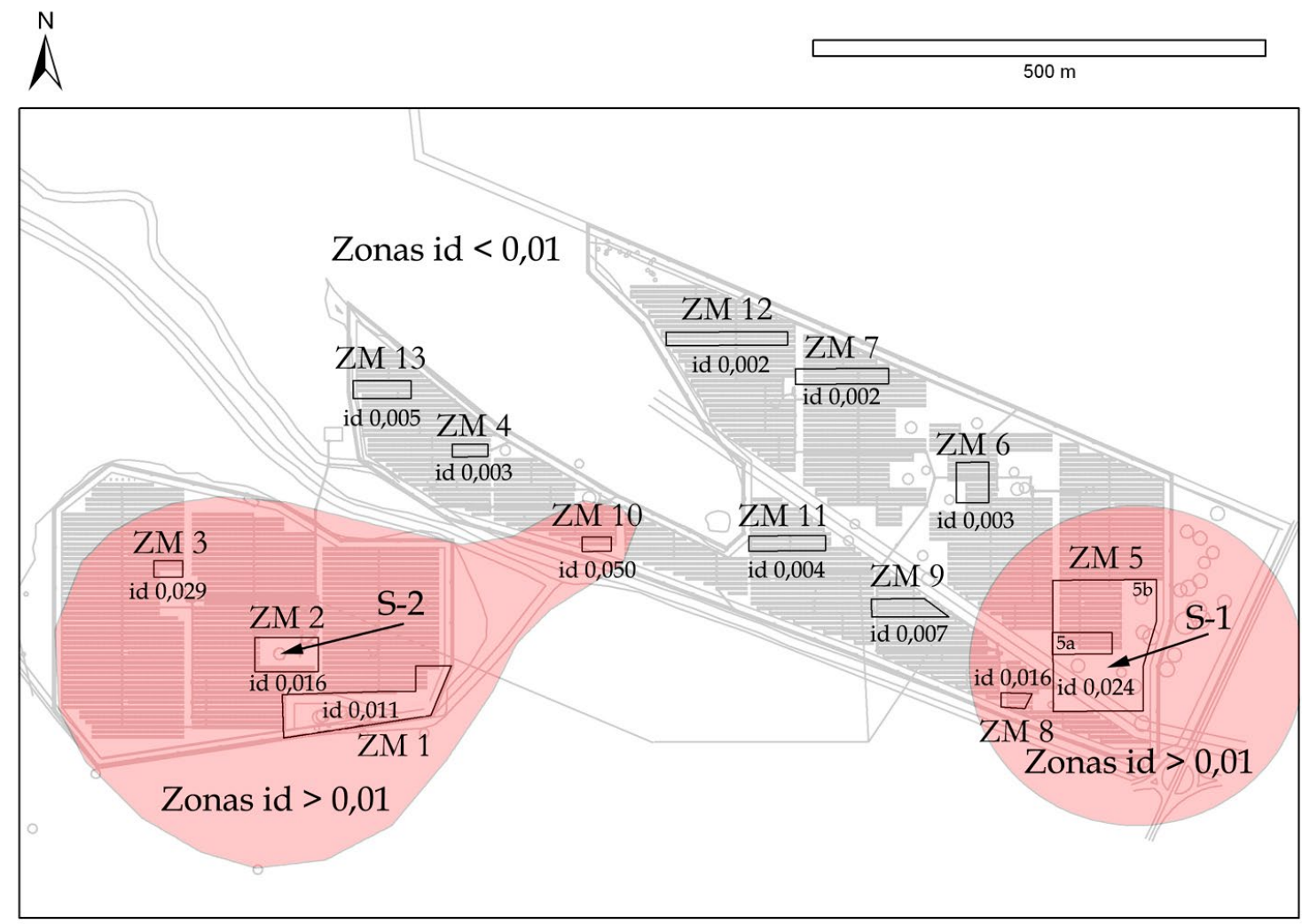

Figura 3: Áreas de prospección, índice de dispersión y localización de los sondeos (S-1 y S-2).

\section{LA PROSPECCIÓN ARQUEOLÓGICA (RE- COGIDA DE DATOS)}

Los trabajos de prospección realizados han consistido en un muestreo aleatorio sistemático, seleccionando y delimitando una serie de zonas dentro de dos parcelas situadas en el término municipal de Cañamero, en la provincia de Cáceres (Fig. 3). ${ }^{1}$

El objetivo de este muestreo sistemático era tener una referencia del índice de dispersión de artefactos (id) por áreas. Los resultados de esta primera valoración pueden verse en la figura 3. En primer lugar, se delimitaron un total de 13 zonas o unidades de muestreo. Dentro de ellas se recogieron y coordenaron todos los elementos arqueológicos visibles mediante un receptor manual GPS, tras lo que se estableció un índice de dispersión por unidad de superficie. Estos datos se volcaron posteriormente a un SIG donde se hizo una estimación para el total de las parcelas, delimitando las zonas de mayor densidad de materiales líticos (Álvarez Alonso y Fernández Fernández, 2012).

Se pueden observar las áreas seleccionadas con su índice de dispersión y la densidad estimada, a

\footnotetext{
1. Estos trabajos se enmarcan en una intervención de urgencia realizada por la empresa TERA S.L. en los terrenos donde se instaló una planta solar fotovoltaica.
}

partir de estos datos. Esta información facilitó la selección de las zonas donde realizar los sondeos (S-1 y S-2).

\section{CONTEXTUALIZACIÓN DE LOS DATOS}

Es abundante la literatura que se ha dedicado a evaluar el valor de los yacimientos «superficiales» como el que aquí estudiamos, dentro de la línea teórica denominada generalmente como off-site archaeology, (Cherry et alii, 1988; Dunnell y Dancy, 1983; Rossignol y Wandsnider, 1992; Diez Martín, 1997). Estos enfoques priorizan el valor contextual de los artefactos, por lo que en ellos juega un papel fundamental el estudio espacial o territorial. Dentro de estos planteamientos es fundamental la evaluación de los procesos postdeposicionales a los que ha estado sometido el registro, sin cuyo conocimiento no se puede desarrollar su adecuada contextualización. Siguiendo a D. Clarke (1984), los procesos deposicionales y postdeposicionales son claves y han de ser tenidos en cuenta, antes incluso de poner en marcha cualquier análisis de datos o de diseñar un modelo para la interpretación de los mismos. Por esta razón, debíamos tener en cuenta dos aspectos fundamentales que sin duda influyeron en la alteración de las zonas prospectadas. Por un lado el contexto geomorfológico, las rañas: superficies aplanadas sometidas 
a diferentes procesos erosivos durante el Pleistoceno. Por otro, la acción del arado, de la que tenemos constancia histórica en los terrenos objeto de estudio. Los siguientes apartados estarán dedicados a analizar dichos aspectos.

\subsection{CONTEXTO GEOMORFOLÓGICO}

La raña de Cañamero se localiza en el Macizo Ibérico, dentro de la denominada zona Luso-Oriental Alcudiana, que a su vez se divide en tres conjuntos principales: el sinclinal de las Villuercas, constituido principalmente por materiales ordovícicos y silúricos; el anticlinorio Precámbrico de Guadalupe-Ibor y el anticlinorio Precámbrico denominado Centro-Extremeño. Las rañas son superficies de acumulación que se habrían originado durante el Plioceno medio-superior, formadas por materiales terciarios y cuaternarios, que fosilizan las series anteriores (Hernández Pacheco, 1949; Espejo, 1987; 1988). Son amplias plataformas amesetadas situadas a modo de interfluvio entre la red de drenaje cuaternaria. La de Cañamero, actúa de divisoria entre los ríos Ruecas y Silvadillos-Guadalupejo, situándose al norte de esta formación una serie de elevaciones cuarcíticas (Sierra de las Villuercas) con valores de altitud en torno a los $745 \mathrm{~m}$ (1600 m de elevación máxima). Tras su formación, las rañas han estado sometidas a importantes procesos erosivos durante el Cuaternario, principalmente provocados por el encajamiento de la actual red fluvial, que desmantela estas superficies como consecuencia de la acción remontante en cabecera de los cauces. A estos procesos habría que sumar, según Espejo (1988), la importante pérdida de suelo por erosión laminar, que en la raña de Cañamero estaría constatada por la acumulación residual de elementos gruesos cuarcíticos en la parte superior o convexa de las vertientes. La erosión laminar produce una selección de partículas (quedando las más gruesas y desplazándose las más finas). Este dato es especialmente interesante para valorar los procesos postdeposicionales a los que ha estado sometido el yacimiento. El desgaste de algunas piezas, en contraste con otras, podría mostrar que se habrían producido sucesivos ciclos erosivos que afectarían de forma distinta a las diferentes partes del yacimiento. La baja permeabilidad de los suelos de raña y su relieve suave favorecen la aparición de charcas estacionales, dato interesante desde el punto de vista antrópico, como queda patente actualmente al ser empleadas por los ganaderos como abrevadero para los animales (Álvarez Alonso y Fernández Fernández, 2012).

\subsection{LA EROSIÓN SUPERFICIAL DE LA RAÑA Y LOS CON- TEXTOS ARQUEOLÓGICOS EN MEDIOS EDÁFICOS}

Los suelos son sistemas complejos y dinámicos, afectados por innumerables procesos de tipo químico, físico o biológico. Por lo tanto, durante el proceso de formación de un suelo se da una secuencia de sucesos que pasan por: la alteración del sustrato basal, produciendo materia mineral, que luego será colonizada por vegetales que aporten materia orgánica en un proceso de humificación, para finalmente producirse una reorganización de todos estos componentes.

Pero hay que destacar que no sólo concurren procesos de alteración, formación y consecuente engrosamiento; en la edafización también intervienen otros fenómenos como la isotropización o haplodización, que consiste en la pérdida o atenuación de horizontes (Pedraza, 1996), siendo además las distintas capas del suelo afectadas igualmente por procesos generales como la iluviación o eluviación. Estos fenómenos nos interesan especialmente en nuestro caso, ya que se trata de hechos constatados en los procesos erosivos que afectan a la superficie de la raña, entre los que destaca la «erosión laminar» (Espejo, 1988; Mariscal, 2008).

Por otra parte, cuando localizamos materiales arqueológicos en un suelo, debemos actuar con precaución, siendo lo primero que debemos evaluar el carácter del mismo, y la relación que existe entre el material arqueológico y el mencionado suelo. De este modo, podremos discernir entre «suelos arqueológicos» $\mathrm{u}$ horizontes de ocupación / asentamiento / actividad humana, y meros «horizontes edáficos» con material arqueológico incorporado a su proceso formativo. En este último lugar habrá que explicar, además, la presencia de materiales en dicho contexto.

Es importante, como ya advertíamos al principio, efectuar un profundo análisis tafonómico y geoarqueológico, comprendiendo tanto el conjunto lítico como el contexto en el que éste se halla, y procurando reconstruir, en la medida de lo posible, la historia tafonómica del lugar.

En el caso de tratarse de un material no desplazado ni horizontal, ni verticalmente (aunque descontextualizado), puede presuponerse una posición primaria (aunque no por sedimentación, más bien por localización). Ahora bien, al estar inmerso en el propio proceso pedogénico y sometido a todas las alteraciones a las que puede estar sujeto dicho suelo (como el laboreo agrícola), no podemos considerar tampoco estos materiales como localizados en una posición primaria sensu stricto.

A lo largo del Cuaternario, la raña de Cañamero ha experimentado intensos procesos postdeposicionales como consecuencia de la acción de los procesos edafogénicos (Espejo, 1988). Según Mariscal (2008) algunas de las características de los suelos de la raña serían:

-Intensa alteración de los sedimentos de raña, que ha provocado la desaparición de pizarras, esquistos y grauvacas, y su integración en la matriz.

-Arenización de las cuarcitas por disolución del cemento silíceo.

-Fuerte lavado y desaturación de todo el espesor de la formación, que aparece edafizada en su totalidad. 
-Ausencia de límites textuales abruptos, existiendo un horizonte $\mathrm{AB}$ entre el epipedión y el horizonte $\mathrm{Bt}$, siendo un carácter propio de los suelos de raña más antiguos.

Todos los suelos de la raña se pueden clasificar dentro del orden de los Ultisoles, aunque luego se pueden subdividir en función de la mayor o menor presencia de materia orgánica, aportada fundamentalmente en la actualidad por alcornoques, madroños y brezales, lo cual ya nos aporta un primer factor de alteración dentro de las primeras capas del suelo. Los Ultisoles son suelos antiguos, asociados a morfologías estables (como las rañas) y se definen como suelos muy ácidos, fuertemente alterados y lixiviados, factor que debemos tener en cuenta a la hora de analizar el comportamiento y evolución en su interior de materiales arqueológicos. Se trata de suelos que adquirieron sus principales características bajo climas subtropicales, y que no han sido afectados por las últimas glaciaciones ni han sufrido grandes alteraciones geológicas (Mariscal, 2008).

En consecuencia, y teniendo en cuenta que la raña es una formación sedimentaria de edad Plioceno medio-superior, el recubrimiento edáfico presente debería englobar todo lo acontecido a lo largo del Cuaternario, ya que su formación se iniciaría en un momento muy temprano, incluso anterior al inicio del Pleistoceno. Por otra parte, la delgadez del horizonte edáfico presente y la única presencia de materiales asignados al Paleolítico medio, debe hacernos reflexionar sobre dos aspectos: los procesos erosivos superficiales a los que han estado sometidos estos suelos (con un intenso lavado) y el hecho de que este lugar aparentemente sólo haya sido transitado por grupos neandertales a lo largo del Pleistoceno, lo cual revelaría posibles patrones de conducta antrópica asociados con la raña.

Por otra parte, debemos indicar que no sólo el laboreo agrícola tal y como lo conocemos hoy en día afecta a estos medios, sino que las labores agrícolas y ganaderas de la Prehistoria y los distintos periodos históricos (pastoreo, deforestación, roturaciones...) han afectado a la circulación de las aguas superficiales y subterráneas, a su lixiviación, a la acidificación del suelo, al drenaje y en definitiva a la modificación del mismo, tal y como apunta K. W. Butzer (1982). Debido a esto, no sólo se alteran los componentes del suelo, también su contenido.

La utilización del arado tiende a destruir los horizontes superficiales y a homogeneizarlos, y cabe destacar que, aunque su utilización haya sido abandonada (incluso siglos antes) el horizonte alterado puede cobrar, con el tiempo, el aspecto de un horizonte A que se asienta sobre otro horizonte B (Butzer, 1982), añadiendo más elementos que invitan a la precaución a la hora de analizar estos contextos. Como veremos en el siguiente punto, la acción del arado está constatada, al igual que está constatada una intensa erosión y alteración por parte de los agentes naturales del horizonte edáfico que recubre la raña. Estas circunstancias han provocado que el desarrollo de estos suelos no haya sido, ni muy complejo ni muy amplio, con lo cual, en la actualidad, nos encontramos con horizontes de corto desarrollo y altamente expuestos.

\subsection{ANÁLISIS TAFONÓMICO Y GEOARQUEOLÓGICO DEL YACIMIENTO}

Son abundantes los trabajos que se han dedicado a aclarar el papel que ha jugado el laboreo agrícola en la alteración de los yacimientos en superficie (p.e. Roper, 1976; Lewarch y O'Brien 1981; Odell y Cowan, 1987; Dunnell y Simek, 1995), que tienen su aplicación en la Península en trabajos como los de Díez Martín (1998; 2000; 2003). Los datos indican que las actividades agrícolas generan al menos los siguientes tipos de factores: desplazamientos horizontales, desplazamientos verticales y alteración de la forma, contenido y conservación de los conjuntos.

En la raña de Cañamero se realizaron actividades agrarias; lo conocemos gracias a entrevistas realizadas a agricultores actuales que nos indicaron que el espacio estudiado había sido utilizado para el cultivo del centeno. ${ }^{2}$ Por lo que todos los factores enumerados anteriormente habrían jugado su papel en la conformación actual del yacimiento. La acción del arado provoca la exposición de los materiales arqueológicos a los agentes medioambientales, como la lluvia, el frío o el viento, que pueden provocar fenómenos de formación de pátinas por meteorización, eolización, o fragmentación del material arqueológico. Esta acción se manifestaría de forma diferencial, por lo que unos elementos podrían presentar estos síntomas en tanto que otros no.

Los estudios realizados en zonas aradas (p. e. Roper, 1976; Odell y Cowan, 1987; Lewarch y O'Brien, 1981), han mostrado que la acción del arado no implica variaciones significativas de los materiales horizontalmente, y que, en cualquier caso, no se alteran sustancialmente los patrones de distribución de restos líticos. Por su parte, Díez Martín (1998; 2000; 2003) ha observado mediante técnicas experimentales que en líneas generales no se conservan los patrones originales de deposición, aunque sí una asociación bastante aproximada con los puntos geográficos originalmente seleccionados. En cualquier caso, es posible reconocer

\footnotetext{
2. Por los datos que conocemos estos terrenos habrían pertenecido al Marqués de La Romana, y tendrían durante la primera mitad del siglo XX un uso principalmente forestal, por la mala calidad de su suelo. Tras la Guerra Civil los terrenos se fueron parcelando y vendiendo a diferentes propietarios entre las décadas de los 40 y 50 . Algunas de ellas fueron deforestadas y puestas en uso para el cultivo del centeno hasta los años 70 , entre las que se encuentran las parcelas estudiadas. A partir de la década de los 70 nuevamente se produce un cambio de uso, destinándose estos terrenos al mantenimiento de una cabaña ganadera de tipo extensivo (oveja principalmente).
} 
en un sentido laxo, los yacimientos, ya que el arado permite mantener a lo largo del tiempo las vinculaciones originales entre los restos y el lugar primitivo donde se desarrollaron las actividades antrópicas.

Aunque siempre hay que tener en cuenta, tal como indica Díez Martín (1998; 2003), que ante este tipo de yacimientos alterados por el laboreo agrícola, la actuación de fuerzas horizontales y verticales habría propiciado el enmascaramiento de una parte importante de los objetos, produciendo una presencia mayor en superficie de las piezas grandes y un ocultamiento de las de menor porte, impidiendo así una valoración exacta de la relación entre las distintas fases de la Cadena Operativa a partir de la muestra visible.

Mediante la realización de sondeos se puede establecer la relación entre material localizado en superficie y el oculto en el sedimento, más adelante aportamos los resultados al respecto.

\subsection{LOS SONDEOS ARQUEOLÓGICOS Y LA INFLUENCIA DEL LABOREO AGRÍCOLA EN LA RAÑA}

La realización de dos sondeos nos ha mostrado que los horizontes arqueológicos coinciden con la franja alterada por el laboreo agrícola $(25-30 \mathrm{~cm}$ de profundidad), de forma que es imposible localizar contextos arqueológicos no afectados por estos procesos. Se hacía necesaria una estimación de la cantidad de artefactos visibles (en superficie) en relación a los no visibles (englobados en el horizonte A), para corregir las desviaciones presentes en los análisis del material lítico superficial. Algunos autores han realizado experimentos para establecer la relación porcentual de artefactos ocultos/expuestos por la acción del arado y la representatividad de las muestras desde un punto de vista cuantitativo/cualitativo (p. e. relación lascas/núcleos). En general se ha observado que la acción del arado tiende a exhibir en superficie menos del $10 \%$ del total de elementos líticos, permaneciendo el 90\% restante oculto a la prospección de superficie. Además, hay que indicar que los elementos de mayor porte tienden a estar más representados que los de pequeño tamaño, dificultando cualquier intento de establecer relaciones porcentuales precisas entre matrices o macro-utillaje y desbastados (Díez Martín, 1998).

Teniendo en cuenta todas estas consideraciones, excavamos dos sondeos de $2 \times 1 \mathrm{~m}$ con la intención de establecer una relación aproximada entre piezas en superficie y en el paquete de arada, con la siguiente denominación y localización (Fig. 3):

Sondeo 1. Coordenadas (UTM ED50 Huso 30N): 297.997,258 X

4.356.687,986 Y

Sondeo 2. Coordenadas (UTM ED50 Huso 30N): 297.079,998 X

4.356.705,296 Y

Desde el punto de vista estratigráfico los resultados fueron idénticos. Se identificaron dos horizontes, una capa húmica superficial (UE1, de unos 25 a $30 \mathrm{~cm}$ de espesor) y bajo ella el sustrato geológico, compuesto de materiales detríticos de origen terciario (Fig. 4).

En el Sondeo 1 no se localizaron materiales arqueológicos en estratigrafía. Por el contrario, en el Sondeo 2 se documentaron un total de 7 piezas líticas, todas ellas en la Unidad Estratigráfica 1 o superficial. Su distribución, tanto a lo largo del perfil (Fig. 4) como en planta, muestra una disposición aleatoria del material arqueológico a lo largo de la secuencia, sin aparente orden estratigráfico ni espacial, por lo que consideramos que los materiales localizados están en posición derivada.

En total se removieron 1200 litros de sedimento. El porcentaje de piezas por cada 201 ha arrojado un total de $1,66 \%$. Este índice lo establecemos para comparar
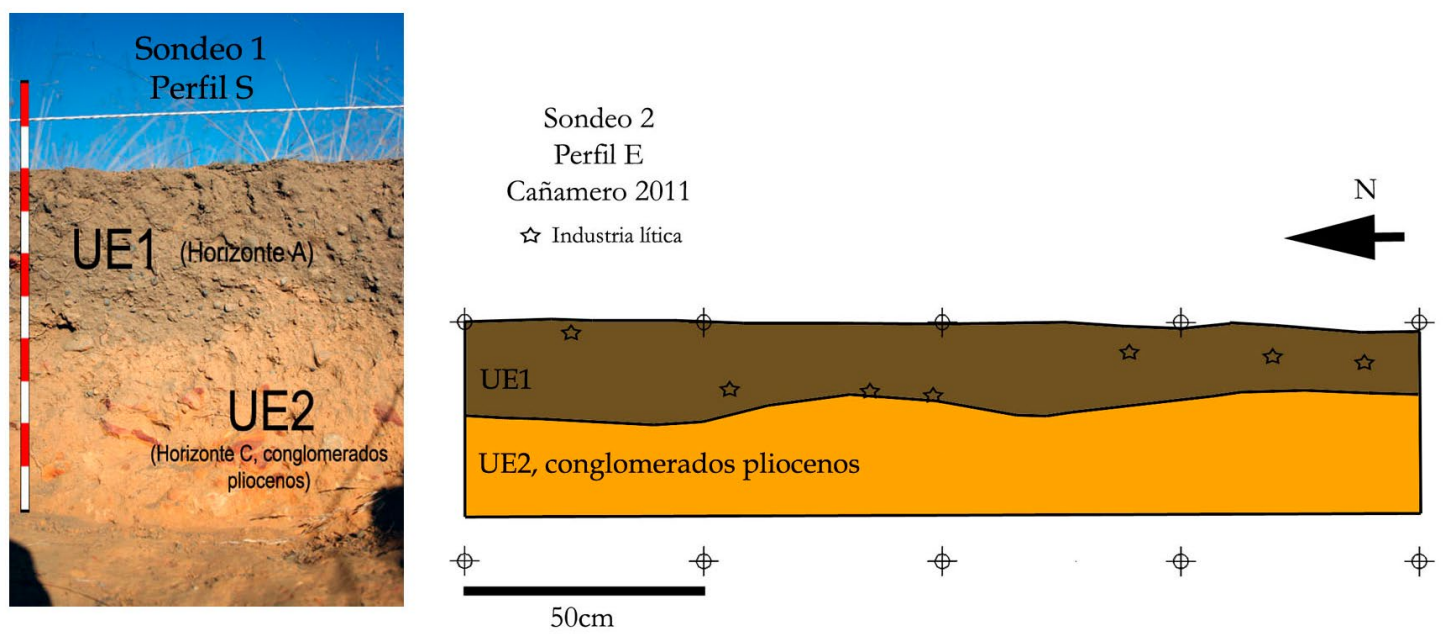

Figura 4: Estratigrafía y perfil de los sondeos realizados. 
con otros estudios similares, como los realizados por F. Díez Martín en la cuenca del Duero a partir de 29 sondeos abiertos en 6 localizaciones diferentes (Díez Martín, 2003), que aportaron datos de densidad entre $0,02 \%$ / 20 , los más bajos, y 2,2\% / 20 1, los más altos.

En la raña de Cañamero observamos un porcentaje muy bajo de elementos en superficie en relación a los englobados en el sedimento. Según nuestros datos tan sólo el $0,7 \%$ de los ítems arqueológicos sería visible. Para realizar este cálculo hemos tenido en cuenta el número total de artefactos en superficie de todas las áreas prospectadas (467) y el promedio estimado en estratigrafía a partir de los dos sondeos (según este cálculo y, siempre teóricamente, en el área prospectada deberían encontrarse más de 64000 piezas englobadas en el sedimento, a razón de 0,006 piezas por litro). En resumen: en la zona prospectada se observaría, en primer lugar, un índice bajo de dispersión de artefactos en superficie (con un promedio de 0,0134/ $\left.\mathrm{m}^{2}\right)$.

Por otro lado apreciamos una baja representatividad de la muestra superficial $(0,7 \%)$, aunque estimamos que la cantidad de útiles englobados en el sedimento aporta datos dentro de la normalidad $(1,66 \% / 20$ 1). Toda esta información apunta en una misma dirección: una escasa alteración del subsuelo si lo comparamos con los trabajos de referencia utilizados (donde las muestras superficiales suelen rondar el $10 \%$, y el porcentaje por cada 201 de sedimento el 1\%). Estas variaciones podrían deberse al tipo de laboreo agrícola utilizado. Los trabajos de arqueología experimental en suelos cultivados que hemos citado se han llevado a cabo en época reciente, tras la introducción de maquinaria pesada en el campo, en tanto que en el espacio de raña que estudiamos se habrían utilizado métodos menos agresivos, antes de su cambio de uso (hacia los años 70 , momento a partir del que se produce la progresiva mecanización del campo en estas regiones). $\mathrm{Si}$ bien es cierto que la acción del arado provoca evidentes alteraciones en los patrones originales de distribución de los artefactos y en su representatividad, no puede compararse la influencia de un arado tradicional con uno mecánico, aunque ambos generarían los mismos tipos de procesos postdeposicionales, pero con una intensidad lógicamente variable. Quizá este aspecto esté relacionado con esta mayor preservación del yacimiento, que según los datos observados podría estar menos alterado o desmantelado que otros yacimientos en superficie. Otro dato a tener en cuenta es que tras su abandono como campos de labor, estos terrenos han tenido un uso pecuario-extensivo, con lo que el pisoteo del ganado habría ocultado de nuevo una parte importante de los conjuntos arqueológicos. También debemos añadir que las características de los Ultisoles que forman el recubrimiento edáfico de la raña, los hacen poco apropiados para el aprovechamiento agrario, debido a la pobreza mineral del sustrato y a la elevada acidez (Mariscal, 2008). En consecuencia, el laboreo agrícola tampoco debió ser una actividad intensiva, centrándose fundamentalmente en cultivos de secano y en la regeneración del suelo a base de un barbecho prolongado.

Por último, debemos anotar que durante las tareas realizadas para la construcción de una planta solar fotovoltaica, se realizaron algunos desbroces de las capas más superficiales, aunque quedaron algunas zonas parcialmente intactas (como la denominada por nosotros 5b: id, 0,016), no apreciándose diferencias notables entre los índices de dispersión de artefactos con respecto a zonas más alteradas por los desbroces superficiales (p. e. zona 5: id, 0,024). Los trabajos fueron más intensivos en la parcela sur, donde ya se introdujo una niveladora, por lo que la alteración de la capa superficial ha sido mucho mayor. Por todo ello somos conscientes de la existencia de una variación importante entre la población real y la muestra recogida en estos terrenos que, como hemos mostrado, han tenido diferentes usos a lo largo del tiempo. También tenemos en cuenta que las estimaciones sobre la cantidad de material arqueológico en estratigrafía, realizadas a partir de tan sólo dos sondeos, únicamente pueden ser aproximativas: conste como ejemplo que todos los elementos de la muestra han sido recuperados en una de las catas.
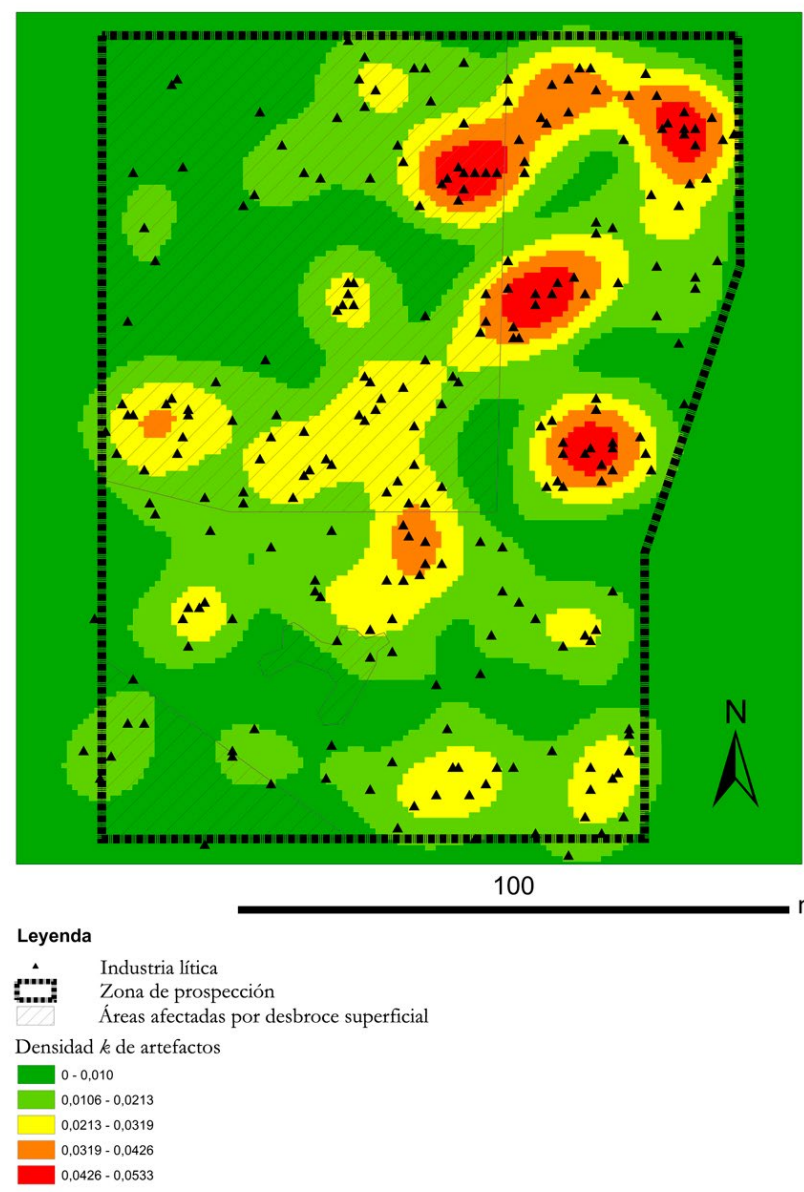

Figura 5: Análisis de densidad $k$ en la Unidad de Muestreo 5. 


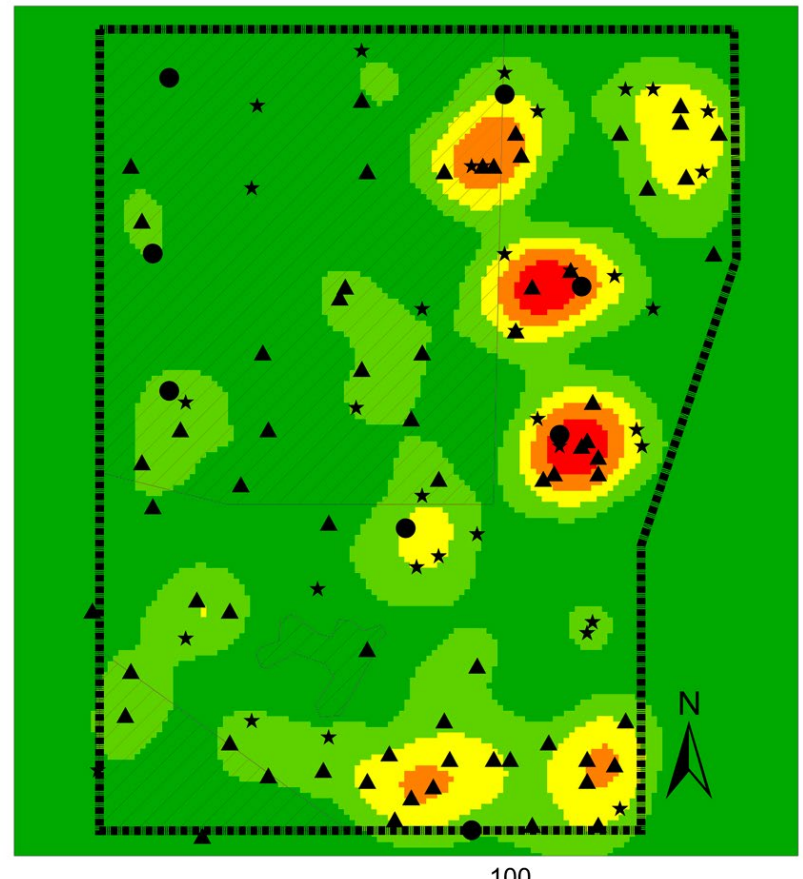

100

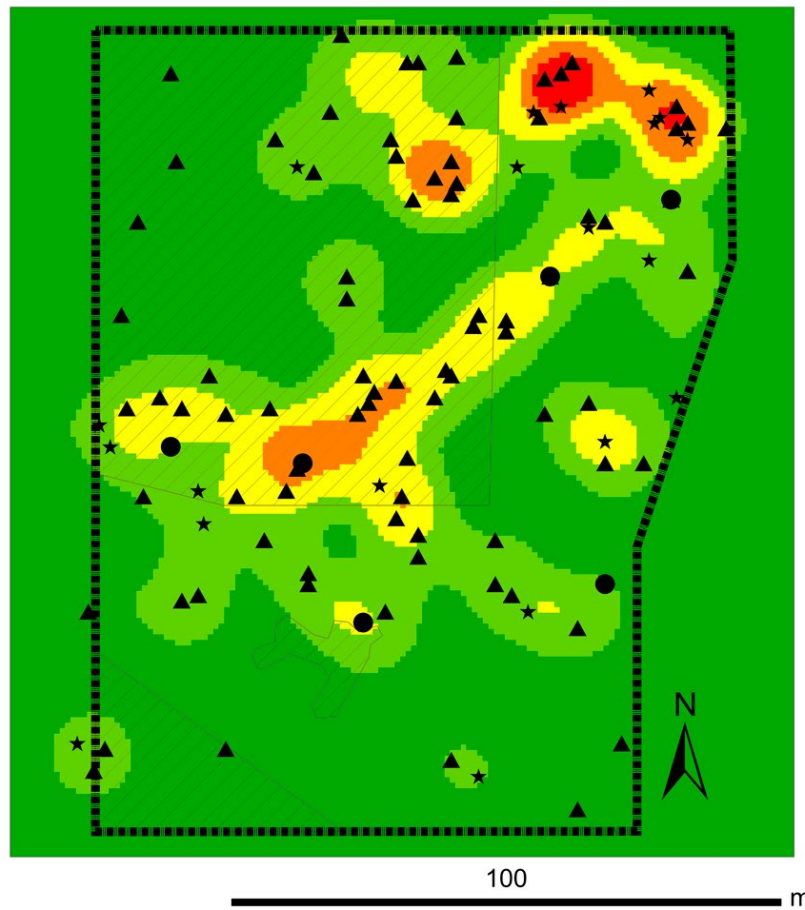

Leyenda

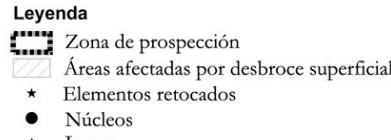

- Núcleos

Leyenda

Zona de prospección

Áreas afectadas por desbroce superficial

Elementos retocados

- Núcleos

Lascas

Figuras 6 y 7: Análisis de densidad kernel en función de la pátina. A la izquierda, elementos con pátinas tipo 1. A la dcha. los de pátina tipo 2. Los análisis de kernel density se hacen partiendo de un radio de $15 \mathrm{~m}$, para compensar el efecto de los errores acumulados por los receptores GPS, la cartografía, o algunos procesos postdeposicionales como la roturación/arada de campos de cultivo. Se trata de aislar patrones de conjuntos en posición derivada, a partir de un nivel de resolución intermedio, que no conservan su distribución original, pero que se mantienen dentro de patrones cuasi-agrupados, sin haber alcanzado un grado de entropía pleno, una distribución homogénea o completamente desestructurada.

Resumiendo: nos encontramos ante un yacimiento que ha sido alterado por diferentes procesos erosivos a lo largo del Cuaternario que, en cualquier caso, no habrían desplazado el material arqueológico de su contexto original (raña). Posteriormente la influencia del laboreo agrícola habría incidido en dicha alteración, aunque su impacto no parece haber sido determinante en el sesgo de material arqueológico. Por ello, la muestra recogida aunque escasa, parece ser suficientemente representativa, pues no se aprecian grandes diferencias cualitativas entre el material preservado en el sedimento y el expuesto en superficie.

\section{ANÁLISIS ESPACIAL Y DISPERSIÓN DEL CONJUNTO}

La información obtenida de la prospección superficial se volcó a una base de datos donde se completó con el estudio tecno-tipológico de la industria lítica recogida. Esta base de datos se vinculó a un SIG para facilitar la visualización espacial de los resultados y permitir diferentes tipos de análisis; por ejemplo, los estudios de densidad de material, cuyo objetivo es apreciar si existe algún tipo de orden o lógica en la distribución de los artefactos, o los análisis de redes, que permiten una mejor contextualización del yacimiento a escala subregional. Se pretendía, de este modo, suplir con la información espacial la falta de contextos estratigráficos.

Para realizar los primeros análisis se seleccionó un área (Zona 5, Fig. 3) que en parte no fue alterada durante la construcción de la planta solar y donde, por tanto, sólo habrían tenido efecto el laboreo agrícola y la erosión laminar. Además, en la parte donde sí se realizaron trabajos, éstos consistieron en un somero desbroce superficial; no se introdujo niveladora del terreno ni otro tipo de maquinaria pesada, por lo que el impacto sobre el terreno fue menor que el de una arada. Los análisis de densidad realizados en esta zona (Fig. 5) nos han permitido aislar espacios de mayor actividad lítica. En la imagen se concretan estas áreas y puede verse que las principales concentraciones están en la parte menos alterada de la unidad de prospección.

Necesitábamos confirmar si estas zonas de mayor acumulación presentaban diferencias cualitativas entre sí, partiendo de los atributos de los diferentes elementos líticos. Para dar respuesta a esta cuestión 


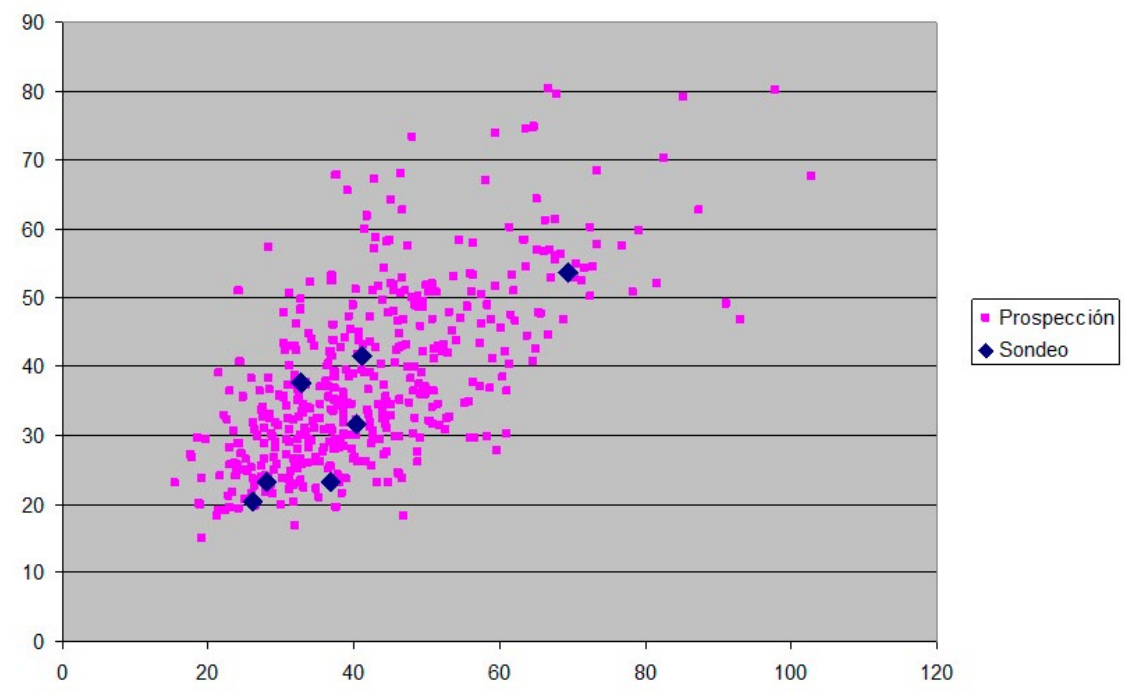

Figura 8: Relación de tamaño de las piezas recogidas en superficie y las localizadas en los sondeos arqueológicos.

realizamos análisis de Kernel Density Estimation (KDE) a través de una plataforma SIG. La KDE es una técnica no paramétrica que coloca una función de probabilidad de densidad bidimensional a través de los puntos observados (artefactos líticos), para crear una aproximación suavizada de su distribución centrífuga desde el centro del punto (Conolly y Lake, 2006). Para realizar estos análisis hemos partido de atributos relacionados con procesos tafonómicos, como el grado de alteración de las piezas, o tipométrico, relacionando el tamaño de los artefactos. Esto nos permite profundizar en la valoración del impacto que algunos procesos postdeposicionales habrían tenido en la formación del yacimiento (Álvarez Alonso y Fernández Fernández, 2012).

El primer atributo que hemos tenido en cuenta es el grado de alteración del material, que podría estar tanto detrás de una posible diacronía de conjuntos, como del grado de exposición diferencial de los materiales a la meteorización. Dos elementos de la misma cronología podrían presentar diferentes grados de alteración; por tanto, se hacía necesario confirmar si de algún modo esta característica estaba o no relacionada con algún otro atributo, como el tamaño de las piezas o las variables tecnológicas.

Tras un primer análisis se han establecido dos zonas de distribución diferencial, especialmente al sur de la parcela seleccionada, donde hay una mayor concentración de elementos con menor desgaste (Fig. 6). Por otro lado se aprecia una ligera abundancia de elementos con más pátina en la parte occidental (Fig. 7). En el resto del área hay una mezcla de ambos tipos (dejamos fuera del análisis el número de piezas pertenecientes al tipo 3, con mayor desgaste, por su menor representatividad: 7 elementos). Esto podría indicarnos distintos grados de alteraciones de origen natural sobre el suelo (menos predecibles y más aleatorias), más que una gran afección del laboreo agrícola sobre el terreno. De ser este último el causante, habría afectado a la superficie y al continente de una forma más homogénea (sobre todo en un área tan reducida).

¿Pueden estar otro tipo de procesos (como los tecnológicos o tafonómicos) relacionados con esta distribución espacial por grados de alteración del material? A continuación aportamos algunos datos para dar respuesta a esta cuestión.

En primer lugar, valoraremos la relación del grado de alteración de las piezas con su tamaño, pues los procesos de erosión podrían estar detrás tanto de la selección de elementos de diferente tamaño, como de una acción erosiva diferencial sobre los mismos. Recurrimos aquí al estudio tecnológico de la colección recuperada. Sobre los datos obtenidos calculamos la relación entre dos variables mediante un análisis de correlación. Por un lado el volumen aproximado (V $=$ longitud $\mathrm{x}$ anchura $\mathrm{x}$ espesor) $\mathrm{y}$ por otro el grado de desgaste de la pátina. El resultado final es 0,0471, por lo que no se observa ningún grado de correlación entre ambas variables: volumen y pátina son fenómenos que no aparecen asociados en la muestra superficial. Si las piezas más grandes o las más pequeñas hubiesen estado expuestas de alguna forma a procesos de erosión diferentes, las variables utilizadas deberían presentar un grado de correlación alto (cercano a 1 ó -1) y no es así.

Este dato se corresponde con lo observado en el estudio estratigráfico. No se aprecia diferencia entre los tamaños de las piezas recuperadas en el sedimento y las piezas recogidas en superficie (Fig. 8).

Otro indicador más de que no ha habido una influencia fuerte del laboreo agrícola en la selección del material. En suelos de arada contemporáneos los elementos de mayor tamaño están más representados en las series superficiales y viceversa. Es lo que se denomina «efecto dimensional» (Baker, 1978). Otro dato interesante es que las pátinas de las piezas rescatadas 


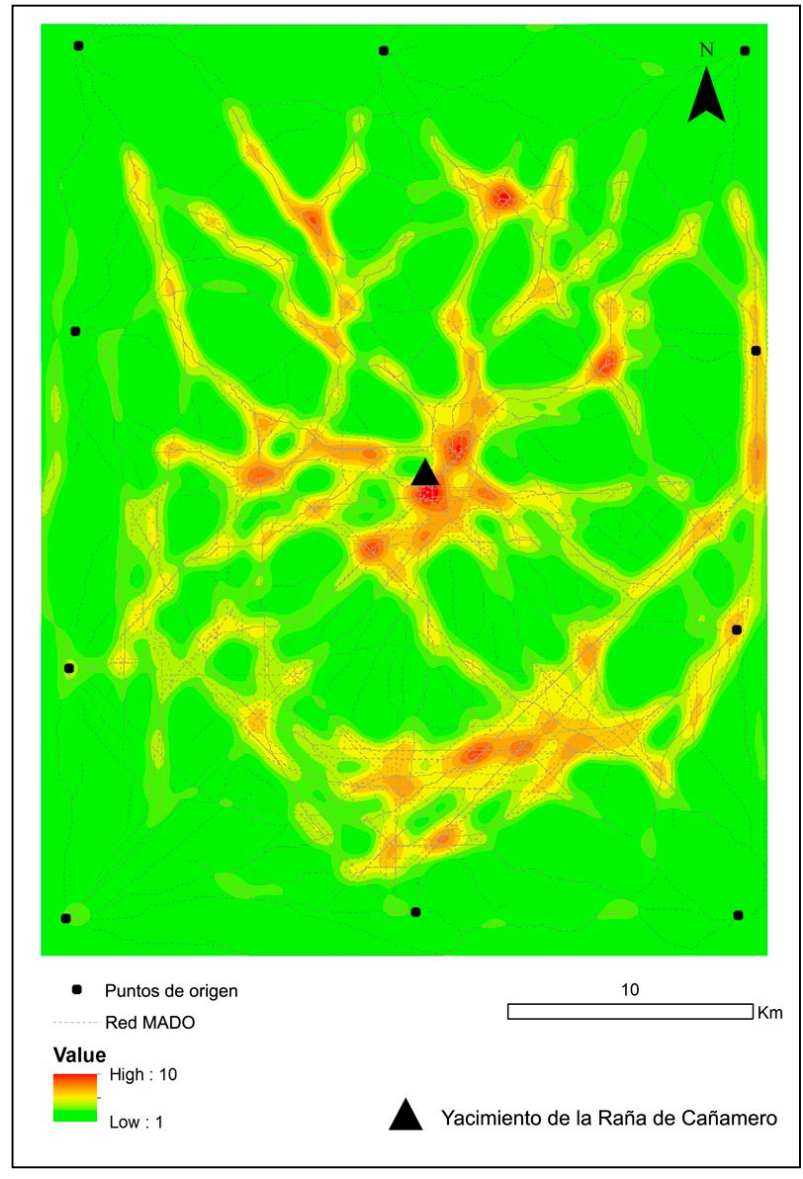

Figura 9: Red de caminos óptimos y densidad de áreas nodales.

en los sondeos son completamente variables (cinco piezas con pátina tipo 1 y 2 piezas con pátinas tipo 3). Por lo que tampoco parece que haya relación entre lo recogido en superficie (donde aparecen igual de representadas todos los tipos de pátinas) y los elementos procedentes del subsuelo.

Ambos datos, la relación tamaño/pátina de la muestra superficial y estratigráfica, parecen por tanto indicar lo mismo: que no hay relación entre el grado de alteración de las piezas y su tamaño. Queda por ver si existe algún patrón de distribución espacial que relacione el grado de alteración del material lítico con algún proceso de tipo tecnológico.

En las imágenes (Figs. 6 y 7) se puede apreciar que, a pesar de los efectos postdeposicionales probados mediante el estudio de la estratigrafía, el análisis espacial muestra patrones de distribución de útiles líticos. Aunque, como ya habíamos visto, la homogeneidad morfotécnica de la colección recogida, tan condicionada por el tipo de materia prima utilizada, también impide a nivel espacial establecer ningún tipo de relación entre grado de alteración, distribución y diacronía.

En resumen, este tipo de yacimientos no muestra información relevante a un nivel de resolución espacial «micro», como consecuencia de la alteración de los contextos arqueológicos primarios. Sin embargo, sí se observan diferencias cualitativas en la distribución de los elementos líticos a una escala superior, entre la micro y la semi-micro. En este sentido, se puede afirmar que el yacimiento estudiado se conserva en un contexto cuasi-primario (en realidad esta definición, sensu stricto, podría ser válida para cualquier depósito de naturaleza arqueológica) y por ello es fundamental utilizar un protocolo de trabajo adecuado para evitar que este tipo de información espacial pase inadvertida.

\section{CONTEXTUALIZACIÓN REGIONAL DEL YACIMIENTO}

\subsection{ANÁLISIS DE REDES}

¿Por qué se ocupó la raña de Cañamero durante el Paleolítico Medio? ¿Fueron factores estructurales-geográficos los que condicionaron estas pautas, o existieron otras causas? Para arrojar algo de luz sobre esta cuestión decidimos realizar un análisis de la movilidad general en una amplia zona $\left(1000 \mathrm{Km}^{2}\right.$ aproximadamente) alrededor de nuestro yacimiento. Buscábamos con ello estudiar la accesibilidad e interconectividad locales de forma hipotética.

Generalmente, cuando se utilizan algoritmos en un SIG para trazar rutas óptimas de menor coste sobre modelos digitales de elevaciones, el objetivo es identificar caminos entre dos puntos, que suelen ser yacimientos (Conolly y Lake, 2006). En nuestro caso lo que buscábamos era analizar la movilidad potencial como una categoría independiente de los datos arqueológicos que manejamos. Queríamos, de esta forma, observar si este análisis paralelo mostraba o no alguna complementariedad con los resultados arqueológicos.

Para implementar este modelo se utilizó una plataforma SIG y un Modelo Digital de Elevaciones (IGN, hojas 50-707 y 50-732), teniendo en cuenta que la orografía es el más determinante de los factores que influyen sobre el desplazamiento. Sobre este MDE se aplicó un algoritmo de movilidad, al objeto de transformar los valores de pendiente del MDE en valores de tiempo. Para realizar este cálculo se ha utilizado el algoritmo de movilidad de Gorenflo y Gale (1990), transformando finalmente los valores en $\mathrm{Km} / \mathrm{h}$ por segundos/unidad de superficie:

Donde «V $\mathrm{V}$ » es la velocidad en $\mathrm{km} / \mathrm{h}$, «e» es la base de los logaritmos neperianos o naturales y «S» es la tangente del ángulo de la pendiente. Por tanto, en este modelo la direccionalidad va a estar determinada por una baja impedancia del factor tiempo.

A partir de la plantilla de fricción creada se elaboró un Modelo de Acumulación de Desplazamiento Óptimo -MADO- (Fábrega Álvarez, 2006), utilizando las herramientas de hidrología con las que suelen elaborarse los mapas basados en la dirección local de las cuencas de drenaje. En nuestro caso, en vez de 
utilizar un MDT, aplicamos estas herramientas directamente sobre la plantilla de fricción. El MADO puede ser descrito como «the representation of an accumulation model of lowest cost movement calculated from a given origin and without specific destination points» (Fábrega Âlvarez, 2007), lo que permite valorar la relación en términos de esfuerzo por desplazamiento entre diferentes puntos de forma independiente. Para realizarlo se situaron una serie de puntos en los márgenes del área de estudio (Fig. 9), desde los cuales se realizó el cálculo. Esta capa vectorial de caminos óptimos se rasterizó, dándole valor 1 a todos los píxeles por donde pasaba la red. Posteriormente se realizó una estimación de la densidad mediante el método Kernel (radio $500 \mathrm{~m}$ ), al objeto de identificar mejor las áreas nodales, es decir, aquellas zonas donde se produce una mayor conectividad/confluencia de aristas o «caminos» (Fig. 9).

Hay que tener en cuenta que nos basamos en un modelo de elevaciones actual, es decir, que no «reconstruye» las condiciones orográficas exactas del período que nos interesa estudiar, el Paleolítico Medio, pues no disponemos de los datos paleoambientales, ni del tiempo que requeriría una reconstrucción de estas características. Aunque somos conscientes de las limitaciones de este tipo de análisis, lo habitual es trabajar sobre modelos «actualistas», siendo cualquier tipo de resultado obtenido meramente orientativo. No obstante, debemos tener en cuenta que durante el $\mathrm{Pa}$ leolítico Medio ya se habrían formado todas las unidades geomorfológicas actuales y, en cualquier caso, sólo la red fluvial se presentaría menos encajada, no habiendo afectado su acción remontante en cabecera tan intensivamente a las rañas como en la actualidad. En cualquier caso, si estas plataformas se muestran en nuestro modelo como un lugar de paso preferente, es lógico pensar que durante el Pleistoceno reciente lo habrían sido todavía más, pues sería más fácil acceder a ellas desde unos fondos de valle más elevados. Por todo ello consideramos suficientemente representativos estos resultados a pesar de su relativo «actualismo» implícito.

El objetivo final, como decíamos al principio, era valorar si el factor movilidad fue importante o no en la ubicación del yacimiento paleolítico de la raña de Cañamero.

Podemos apreciar, en este sentido, que la zona donde se localiza el área de ocupación paleolítica es una de las tres con mayor confluencia de rutas de menor coste de toda el área estudiada (1000 $\mathrm{Km}^{2}$ aprox.), por lo que parece que la accesibilidad e intercontectividad del lugar es la que pudo haber determinado la presencia del yacimiento actual.

Vistos estos datos, es probable que la raña de $\mathrm{Ca}$ ñamero fuese un lugar de confluencia de distintas rutas preferentes de paso durante el Paleolítico Medio, donde multitud de visitas y actividades esporádicas habrían sido recurrentes a lo largo del período. De esta forma se irían acumulando gran cantidad de elementos materiales, que hoy, tras haber estado sometidos a diversos procesos postdeposicionales, se nos presentan dispersos en un suelo contemporáneo.

El punto donde se encuentran los materiales es un espacio intermedio entre las cabeceras de diferentes cuencas. El acceso más rápido y directo entre ellas se haría por este lugar, que además permite cierto control visual de los recursos de ribera. Por tanto, la raña sería un lugar principalmente de paso, aunque la presencia constante de grupos humanos haría más probable la explotación de cualquier recurso subsistencial disponible.

\subsection{ANÁLISIS DE CUENCAS VISUALES}

¿Pudo la visibilidad haber influido de algún modo en la presencia de neandertales en la raña, como parece que ocurrió con la movilidad? Para responder a esta pregunta nos basamos en el análisis de cuencas visuales (viewshed). El análisis de la visibilidad, o cuenca visual, ha tenido en los últimos años un importante desarrollo en la Arqueología y algunos autores consideran que es una de las mayores contribuciones de los SIG al estudio del paisaje (Wheatley y Gillins, 2002). La práctica totalidad de los software de análisis geográfico que hoy día se utilizan ofrece alguna herramienta para realizar el cálculo de cuencas visuales. Este procedimiento consiste en fijar un punto de origen sobre un MDE, para después obtener, mediante la utilización de diferentes algoritmos, un archivo «booleano» con la distribución de los píxeles que serían visibles y no visibles desde el observatorio elegido.

El paisaje visual ha sido definido por M. Llobera (2003) como la representación espacial de cualquier propiedad visual generada por, o asociada a, una configuración espacial. Generalmente la configuración espacial de la que parten los arqueólogos son los distintos tipos de yacimientos adscritos a un período, cronología o tipología. Sin embargo existe otra forma, más indirecta, de valorar el peso que la visibilidad ha podido tener en la distribución y/o ubicación de yacimientos arqueológicos. Se trata de acercarse al Paisaje Visual Total, clasificando la superficie de un territorio en función de su mayor o menor visibilidad desde el resto del espacio. Aunque para calcular la cuenca visual total necesitaríamos un observatorio por unidad de superficie (píxel), lo que haría casi imposible el cálculo, simplificamos el proceso mediante una cuantificación más parcial que consiste en calcular una cummulative viewshed (Wheatley, 1995). La cuenca visual acumulada puede ser definida como la suma de diferentes cuencas visuales calculadas desde varios puntos (Llobera, 2003). En nuestro caso sobre una muestra aleatoria de 20 puntos distribuidos sobre el MDT. De cada uno de ellos hacemos el cálculo de la visual y posteriormente, mediante álgebra de mapas, realizamos un sumatorio de las 20 cuencas obtenidas (Fig. 10). En vez de partir de una serie de yacimientos, 


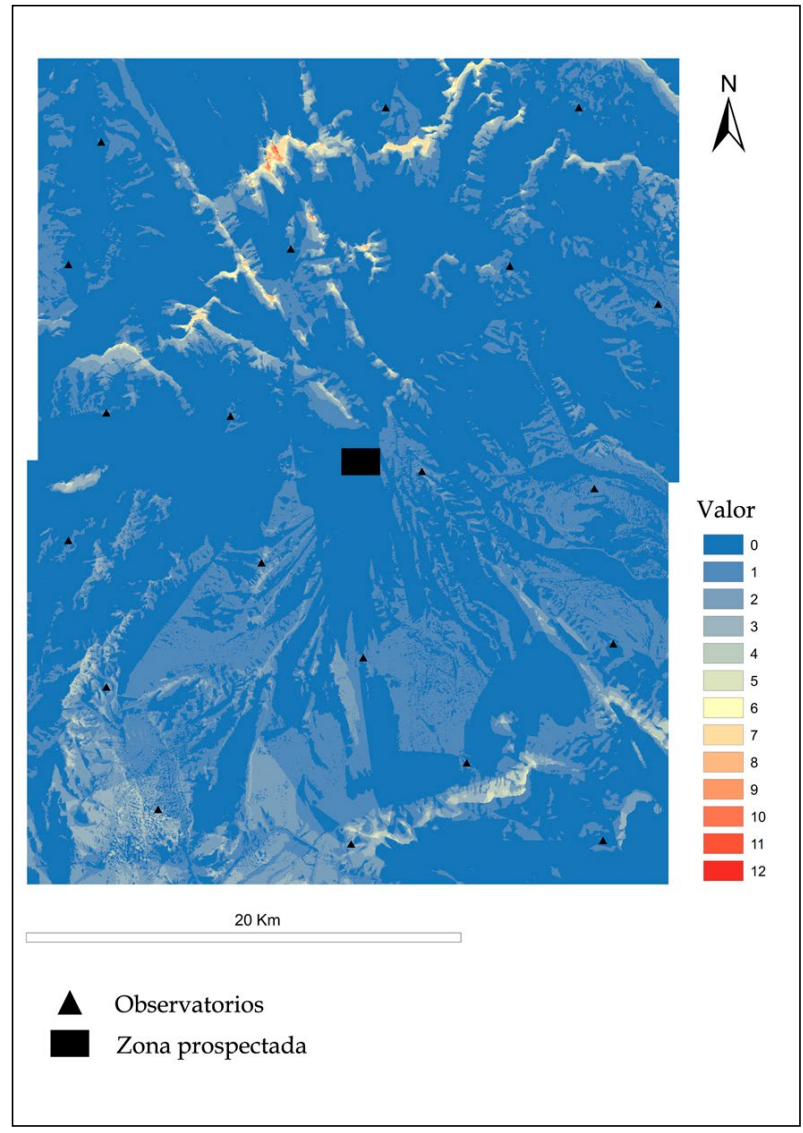

Figura 10: Cuenca visual acumulada a partir de 20 puntos de observación distribuidos en la zona de estudio. Cada valor indica la cantidad de observatorios desde los que es perceptible un área.

intentamos aproximarnos a las características intrínsecas del paisaje, cuantificando un fenómeno de carácter perceptivo, como es la visibilidad, para comparar después la relación con otros elementos (p. e. la distribución de sitios arqueológicos). Con los datos obtenidos concluimos que la visibilidad no parece haber sido una variable de peso en la ubicación del yacimiento. En una escala de visibilidad creciente, de 0 a 12 , la raña da valores entre 0 (zona superior) y 2 (vertientes). En cualquier caso, no se trata de establecer el peso exacto de una variable, sino de extraer una conclusión más sencilla: entre la movilidad y la visibilidad, es la primera la que parece haber determinado más la existencia del yacimiento paleolítico estudiado.

\section{CONCLUSIONES}

El conjunto lítico de la raña de Cañamero se encuentra desprovisto de su contexto original de sedimentación, ya que el laboreo agrícola ha alcanzado todo el paquete edáfico, removiendo $\mathrm{y}$ descontextualizando el material, aunque no exponiéndolo en su totalidad fuera del paquete estratigráfico. Mediante el análisis tafonómico realizado a la industria, se pudo apuntalar esta tesis de una manera concluyente. En esta raña ha sido descrita una importante acción erosiva sobre su superficie, alterando su contenido y continente (Espejo, 1988; Mariscal, 2008), tanto a causa del viento como de la escorrentía superficial ocasional, lo cual encaja perfectamente con las alteraciones observadas en la industria lítica. Por otra parte, no se han observado alteraciones generadas por el transporte o arrastre del conjunto industrial en un medio fluvial (rodamiento, golpeo, estrías...).

Los análisis tecnotipológico y tafonómico del conjunto industrial se plantearon en paralelo (Álvarez Alonso y Fernández Fernández, 2012). El objetivo se centró en evaluar la existencia de alteraciones constatables en el conjunto, que se podrían manifestar con la ausencia (por eliminación) de efectivos a causa de agentes erosivos de origen natural. El resultado fue negativo, ya que no se pudo determinar ningún tipo de sesgo con valor tafonómico en la muestra analizada, dando como resultado un conjunto industrial muy homogéneo y bastante completo, desde la perspectiva de las Cadenas Operativas identificadas (Álvarez Alonso y Fernández Fernández, 2012). Tampoco hay separación tecnotipológica con valor diacrónico a partir del análisis de pátinas.

En consecuencia, los procesos erosivos y de arada han alterado el contexto arqueológico primario. Sin embargo, los desplazamientos horizontales y verticales, no habrían introducido un sesgo excesivamente importante en el registro, ni habrían desplazado el yacimiento de su contexto inmediatamente secundario (que también podríamos denominar cuasi-primario). Esta alteración de la disposición original del registro impide trabajar a un nivel «micro» de resolución espacial. Sin embargo, al variar el factor de escala hasta un nivel de resolución menor (semi-micro), el yacimiento recupera cierta estructura espacial, lo que permite la aplicación de métodos de análisis distribucional.

El examen intra-site realizado revela posibles zonas de uso diferencial del espacio durante el Paleolítico medio, sin poder precisar si se trata de procesos naturales o diacrónicos. Las características morfotécnicas de las industrias recogidas, muy homogéneas por estar fuertemente condicionadas por los soportes, impiden cualquier valoración que relacione tecnología y cronología. En cualquier caso, a nivel metodológico mostramos una herramienta útil, pues sí podrían haberse dado estas diferencias, que pasarían inadvertidas sin la puesta en marcha del protocolo de investigación desarrollado.

Por otro lado, el estudio de las variables macroespaciales (redes y visibilidad), indican una gran dependencia por parte de los grupos de cazadores-recolectores del factor movilidad. La raña se presenta como un lugar preferente de paso, lo que explicaría la abundancia de material arqueológico, que resultaría de la presencia recurrente de paradas o estancias efímeras, que aprovecharían los recursos disponibles en cada momento a lo largo de una fase temporal de amplia duración (Paleolítico medio sensu lato), dando lugar de este modo a la formación del yacimiento de la raña de Cañamero. 


\author{
Jesús Fernández Fernández \\ La Ponte-Ecomuséu \\ Barrio San Romano s/n \\ Villanueva de Sto. Adriano \\ 33115 (Asturias) \\ David Álvarez Alonso \\ Departamento de Prehistoria y Arqueología \\ C.A. UNED-Asturias \\ Avda. Jardín Botánico 1345 (Calle interior) \\ 33203 Gijón \\ dalvarez@gijon.uned.es
}

\section{BIBLIOGRAFÍA}

ÁLVAREZ ALONSO, D. y FERNÁNDEZ FERNÁNDEZ, J., 2012: «El conjunto lítico musteriense de la raña de Cañamero (Cáceres, España). Análisis tecnotipológico y tafonómico», Munibe, 63, 27-43.

BAKER, CH. M., 1978: «The size effect: an explanation of variability in surface: artifact assemblage content», American Antiquity, 43, 288-293.

BUTZER, K. W., 1982: Arqueología, una ecología del hombre, Barcelona.

CHERRY, J. F., DAVIS, J. L., DEMITRACK, A., MANTZOURANI, E., STRASSER, T. F. y TALALAY. L. E., 1988: «Archaeological survey in an artifact-rich landscape: A Middle Neolithic example from Nemea, Greece», American Journal of Archaeology, 92, 159-176.

CLARKE, D., 1984: Arqueología analítica, Barcelona.

CONOLLY, J. y LAKE M., 2006: Geographical Information Systems in Archaeology, Cambridge (edición española, Bellaterra, 2009).

DIEZ MARTÍN F., 1997: «Reflexiones sobre la arqueología superficial: Valoración de su problemática y utilidad potencial en los yacimientos paleolíticos de la Meseta», Boletín del Seminario de Estudios de Arte y Arqueología, 63, 9-29.

DIEZ MARTÍN F., 1998:«Observaciones sobre la incidencia del laboreo agrícola en los agregados líticos. El experimento de Las Cuestas (Tudela del Duero, Valladolid)», Boletín del Seminario de Estudios de Arte y Arqueología, 64, 29-40.

DIEZ MARTÍN F., 2000: El poblamiento paleolítico en los páramos del Duero, Studia Archaeologica $\mathrm{n}^{\circ} 90$. Valladolid.

DIEZ MARTÍN F., 2003: «Las alteraciones inducidas por el laboreo agrícola: la influencia del movimiento vertical en los yacimientos paleolíticos de los páramos de Montemayor-Corcos (Valladolid y Burgos)», Zephyrus, 56, 49-60.

DUNNELL, R. C. y DANCY, W. S., 1983: «The siteless survey: A regional scale data collection strategy», en M. B. SCHIFFER (Ed.), Advances in Archaeological Method and Theory, Vol. 6, 267-287.

DUNNELL, R. C. y SIMEK, J., 1995: «Artifact size and plowzone processes», Journal of Field Archaeology, 22, 305-319.

ESPEJO, R., 1987: «The soils and ages of the «raña» surfaces related to the Villuercas and Altamira mountain ranges (Western Spain)», Catena, 14, 399-418.
ESPEJO R., 1988: «Evolución geomorfológica y procesos erosivos en las formaciones de raña relacionadas con las sierras de las Villuercas y Altamira (W de España)», Ecología, 2, 39-51.

FÁBREGA ÁLVAREZ, P., 2006: «Moving without destination. A theoretical GIS-based determination of movement from a giving origin», Archaeological Computing Newsletter, 64, 7-11.

FÁBREGA ÁLVAREZ, P. y PARCERO OUBIÑA, C., 2007: «Proposals for an archaeological analysis of pathways and movement», Archeologia e Calcolatori, 18, 121-40.

GORENFLO, L. J. y GALE, N., 1990: «Mapping regional settlement in information space», Journal of Anthropological Archaeology, 9: 3, 240-274.

HERNÁNDEZ-PACHECO, E., 1949: «Las Rañas de la sierras centrales de Extremadura», Com. Rendu du XXVI Congrés International de Geographie, 87-109.

LEWARCH, D.E. y O'BRIEN, M.J., 1981: «The expanding role of surface assemblages in archaeological res earch», en M. B. SCHIFFER (Ed.), Advances in Archaeological Method and Theory 4, 297-334, Tucson, Arizona.

LLOBERA, M., 2003: «Extending GIS-based visual analysis: the concept of visualscapes», International Journal of Geographical Information Science, vol. 17, 1, 25-48.

LLOBERA, M., 2006: «Arqueología del paisaje en el siglo XXI: reflexiones sobre el uso de los SIG y modelos matemáticos», en I. GRAU MIRA (Ed.), La aplicación de los SIG en la arqueología del paisaje, 109-124, Alicante.

MARISCAL SANCHO, I., 2008: Recuperación de la calidad de Ultisoles mediterráneos degradados, mediante la aplicación de enmiendas y formas alternativas de uso, Tesis Doctoral, Universidad Politécnica de Madrid.

ODELL, G H. y COWAN, E., 1987: «Estimating tillage effects on artifact distributions», American Antiquity, 52, 456-487.

PEDRAZA, J., 1996: Geomorfología. Principios, métodos y aplicaciones, Madrid, edición 2003.

PEREGRINA ALONSO, F., 2005: Valoración agronómica de residuos industriales yesiferos y calizos. implicaciones sobre la dinámica del complejo de cambio, la disolución del suelo y la productividad en palxerults del oeste de España, Tesis doctoral, Universidad Politécnica de Madrid.

ROPER, D. C., 1976: «Lateral displacement of artifacts due to plowing», American Antiquity, 41, 372-375.

ROSSIGNOL, J. y WANDSNIDER, L. (Eds.), 1992: Space, Time, and Archaeological Landscapes, New York.

WHEATLEY, D., 1995: «Cummulative viewshed análisis: a GIS based method for investigating intervisibility, and its archaeological applications», en G. LOCK y Z. STANIC (Eds.), Archaeology and Geographical Information Systems, 171-185, Cambridge.

WHEATLEY, D. y GILLINS M., 2002: Spatial Technology and Arhaeology. The Archaeological Applications of GIS, Londres. 